\section{FINDING THE OPTIMAL LOCATION FOR A POWER-TO-GAS STATION*}

ŚLĄSKI

PRZEGLĄD

STATYSTYCZNY

$\mathrm{Nr}$ 18(24)

\author{
Mänz Posselt \\ Philipps University of Marburg, Germany \\ e-mail: posselt@wiwi.uni-marburg.de
}

ISSN 1644-6739

e-ISSN 2449-9765

This work is licensed under the Creative Commons Attribution-ShareAlike 4.0 International

License. To view a copy of this license, visit http://creativecommons.org/licenses/by-sa/4.0/

Quote as: Posselt, M. (2020). Finding the optimal location for a power-to-gas station. Ślaski Przegląd Statystyczny, 18(24).

DOI: $10.15611 /$ sps.2020.18.19

JEL Classification: C31

In the control area of the transmission, a system operator for electricity of 50 hertz power production from wind power and photovoltaic overshoots the power demand in $6.9 \%$ of the time (measured in the period between 2015 and 2018). With the expansion of these power sources this ratio will rise. Therefore the question arises how to handle the surplus. One opportunity could be the latest technology of power-to-gas $(\mathrm{p} 2 \mathrm{~g})$ which uses this expanded power to separate water into oxygen and hydrogen. The hydrogen could be used directly or converted under the inclusion of carbon dioxide into methane gas. The methane gas is easily storable or could be used for heating or mobility. The question is, where to locate such a $\mathrm{p} 2 \mathrm{~g}$ station to minimize transportation losses (and maximize the stored power). To answer this question, data from 2015 till 2018 was used on hourly basis.

The model was divided into two sub-models. The first sub-model allocated the generated power (from wind and photovoltaic) to the power consumer. Hence, the surplus power is located geographically. To achieve this a grid with a $27.8 \times 27.8 \mathrm{~km}$ pattern was used. At every node, the power capacity of wind as well as photovoltaic is known from the EEG plant register. Furthermore, weather data (average wind speed and cloudiness) provided by DWD, and overall power supply provided by 50hertz is known as well. With these data, the power supply at every node was estimated. Power consumption is directed to the residents of every commune (85 in total). Therefore, the city Berlin consumes almost $40 \%$ of the total net load. The data of the residents was provided by the census of

*25th Scientific Statistical Seminar „Marburg-Wrocław”. Gollhofen, 23-26 September 2019. Extended abstract. 
2011. Knowing the location and amount of every power source and $\mathrm{Nr} 18(24)$ consumer at every hour, the surplus power could be easily estimated. Assuming that the nearest power supply delivers first, the following map of surplus power could be drawn (see Figure 1).

The second sub-model used the surplus power to find the optimal location for a p2g station, which minimized the transportation losses. This minimization problem could be converted into a maximization problem, where target function $Z$ is maximized over latitude $\phi$ and longitude $\lambda$ :

$$
Z(\phi, \lambda)=\sum_{i=1}^{I} \overline{S_{l}} \cdot(1-\delta)^{d_{i}(\phi, \lambda)} \cdot T,
$$

where as $\overline{S_{l}}$ is the average excess of power supply $i$ over the considered time period $T, \delta$ is the transportation loss each $100 \mathrm{~km}$ and $d_{i}(\phi, \lambda)$ the distance between power supply $i$ and the location of the $\mathrm{p} 2 \mathrm{~g}$ station.

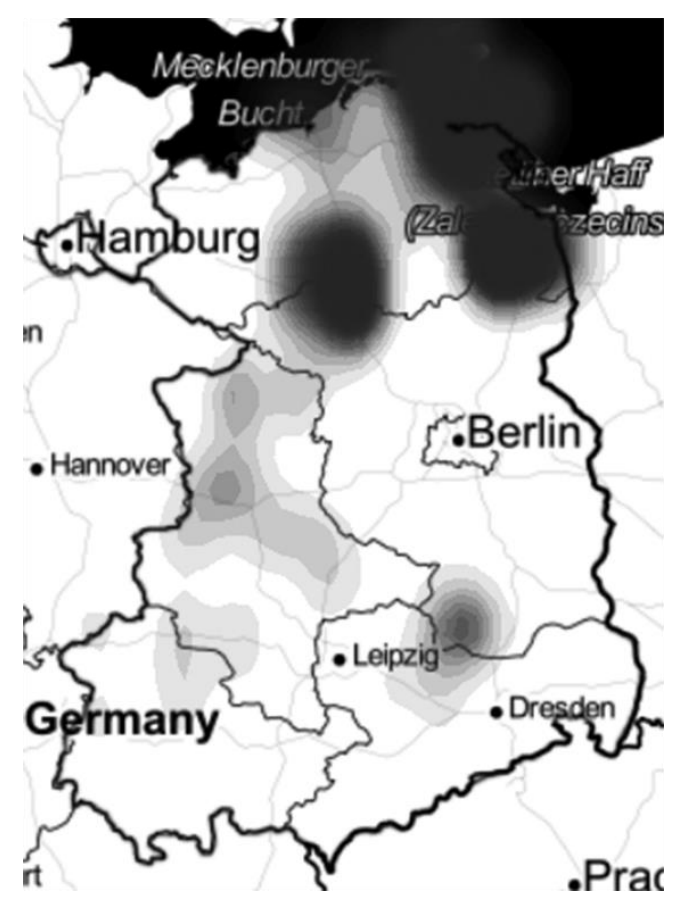

Fig. 1. Map of surplus power

Source: own elaboration.

The maximize the target function a grid search algorithm was used. The global maximum was found at $\phi^{*}=53.8^{\circ} \mathrm{N}$ and $\lambda^{*}=13.3^{\circ} \mathrm{E}$. The following map visualizes the geographical location of the optimal solution (black circle). 


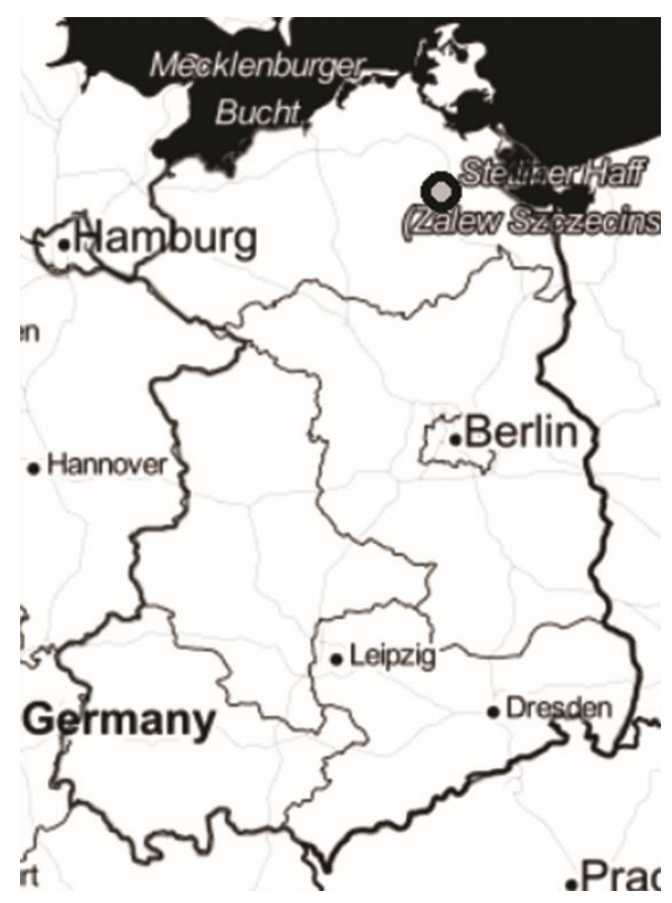

Fig. 2. Map visualizing the geographical location of the optimal solution Source: own elaboration.

One can easily see that this maximum is located in the vicinity of the potential surplus shown in the figure above. Furthermore, this finding is robust, increasing $\delta$ has no effect on the optimal location. A p2g station located at the optimal solution could transfer 4.386 TWh of power in the considered time period. Assume an efficiency loss of 40 percent, 2.631 TWh could be stored or directly used as gas power. Overall, minimized transportation losses led to a $3 \%$ higher usage of excesses power, as opposed to building the $\mathrm{p} 2 \mathrm{~g}$ station at the furthest possible location in the area of 50hertz. However, to use all the surplus, the capacity of the p2g station has to be about $6355 \mathrm{MW}$. This huge capacity is not realizable at this moment in time, but it occurred just for one hour in the whole considered time period. Therefore further work (which is not part of this abstract) should include a capacity limit in the analysis. Hence, more than one possible location is allowed in the optimization. 


\section{Sources}

Nr 18(24)

50hertz - Photovoltaik: https://www.50hertz.com/de/Transparenz/Kennzahlen/Photovol taik [22.08.2019]

50hertz - Windkraft: https://www.50hertz.com/de/Transparenz/Kennzahlen/Windenergie [22.08.2019]

Deutscher Wetterdienst: https://cdc.dwd.de/portal [21.10.2019]

EEG-Anlagenregister: http://www.energymap.info/download.html [22.08.2019] entsoe: https://transparency.entsoe.eu [30.08.2019]

Zensus: https://www.zensus2011.de/DE/Home/Aktuelles/DemografischeGrunddaten [01.10.2019]

Keywords: optimal location, renewable energy, storage size, power-to-gas. 